From the Mental Health Research Institute, University of Michigan

\title{
Time and Dosage Eifects of Meprobamate on Visual Detection
}

\author{
By \\ Arthur Platz*, Leonard Uhr, Margaret Clay, James G. Milier \\ and Alfred B. Kristofferson
}

With 1 Figure in the Text

(Received May 16, 1963)

In spite of the recent interest in the behavioral effects of psychoactive drugs, and the practical importance of the data, there has been little systematic exploration of drug effects on sensory thresholds (Uhr, 1961). Dickes, Flamm, Coltrera, and TobIn (1955) report that mephenesin, a muscle relaxant, increased threshold of both neutral and emotionally charged words presented tachistoscopically. ErsEncK and AIBA (1957) found a lowering of visual threshold under both dexedrine and sodium amytal as compared to a placebo control group. Holland and Treadwerc (reported in Eysenck, 1959) found a general decrease in light sensitivity under meprobamate.

It is known clinically that acute dosages of meprobamate occasionally produce drowsiness as a side effect, and, therefore, it might be expected that the drug would impair performance on a visual detection task demanding sustained attention and accuracy of immediate recall. But since the onset and duration of these drug effects have not been demonstrated empirically, the present study was concerned primarily with tracing out both the time and dosage response curves for meprobamate when administered in acute dosages within the therapeutic range. Response curves on a visual detection task were ascertained for three levels of meprobamate and a placebo at time intervals ranging from 15 minutes to four hours after ingestion. In order to partially control for effects of individual diurnal cycles of activity on performance, the experimental sessions were scheduled for both morning and evening hours.

\section{Method}

Subjects. The subjects were 16 male college students, aged 21 and over, who were paid for their voluntary participation. Because of scheduling difficulties, only 13 of these were also able to participate in the morning tests.

* Arthur Platz is now at the VA Central NP Research Laboratory, Perry Point, Maryland and Alfred B. Kristofferson at the University of Cincinnati. 
Apparatus. Visual threshold was measured by using a four-interval, temporal forced-choice psychophysical method (BLAckWELL, 1953). The visual target, a circular luminance increment subtending one degree at the retina, is superimposed on a large, uniform background of moderate luminance. The target is presented at the fixation point in a location known by the subject. Target exposure duration is 0.010 seconds.

Each trial is defined by four immediately successive time intervals set off by clearly audible clicks. The interval in which the target is presented is determined at random from trial to trial. After each trial the subject indicates his choice by pressing one of four buttons, which automatically records his response. Fifty successive trials constitute a run and require twelve minutes to complete.

Since the target is of the same total energy for all trials, visual detection probabilities can be calculated for successive runs. In order to correct for the probability of being correct by chance $25 \%$ of the time, a transformation of the raw score to adjust for chance "hits" was made for the purposes of data analysis (BLAckwELL, 1953).

Testing cycle. Subjects were tested on two mornings, from 8:00 a.m. to $12: 30$ p.m., and on four evenings, from 5:00 to 9:30 p.m. Testing cycles lasted thirty minutes and were repeated seven times from 5:00 to $9: 30$, with a one half hour break for dinner at $7: 30$, and another half hour break at 8:30. A similar schedule was followed for morning tests, with lunch and rest breaks at 10:30 and 11:30 a.m. respectively. Subjects were instructed not to eat for a period of $1 \frac{1}{2}$ hours prior to each testing session. The first 15 minutes of each cycle consisted of individually administered psychomotor tests and self-report inventories. (These data have been reported separately in UHr, Platz and MrLler, 1963). The second half of the cycle was used for threshold determination, lasting 12 minutes. The seven cycles of threshold determination represent an immediate pre-drug test, and test periods beginning at $1 / 4,3 / 4$, $1 / 4,13 / 4,23 / 4$, and $3 \frac{3}{4}$ hours after ingestion.

Over a period of two weeks immediately preceding the major experiment subjects were given from 8 to 10 hours practice on the detection task in order to minimize practice effects, and tested during a complete dry run of seven cycles to familiarize them with the complete testing procedure.

Since the testing was carried out in a basement under artificial lighting, the illumination during both the visual detection procedure and the behavioral testing was the same throughout the testing cycle for both morning and evening tests. The visual detection task was run in a separate, relatively soundproof room under the low illumination provided by the target screen. 
Drug dosage and design. During the evening runs a placebo and three dosages of meprobamate were used: 400,800 , and $1600 \mathrm{mg}$. In all testings, subjects received four $400 \mathrm{mg}$ capsules, the appropriate proportion of these being drug capsules and the balance being placebo. Doses for the morning runs consisted of 0 and $1600 \mathrm{mg}$. Within each test. ing session the different drug dosages were exactly balanced, and the ordering of drugs was balanced across the 16 subjects. Each subject was tested six times: four evenings, once under each dosage, and two mornings, once under placebo and once under $1600 \mathrm{mg}$ of meprobamate. One morning session was scheduled at the middle of the four evening runs, and the second at the end. The number of subjects who had received each of the four dosages during previous evening tests was thus balanced for the morning tests. A double-blind administration procedure was followed so that neither subjects nor experimenter knew which treatment the subject had received on a specific day.

\section{Results}

The data were analyzed in three steps: (1) analysis of time and dosage effects for the evening tests; (2) analysis of time and drug effects

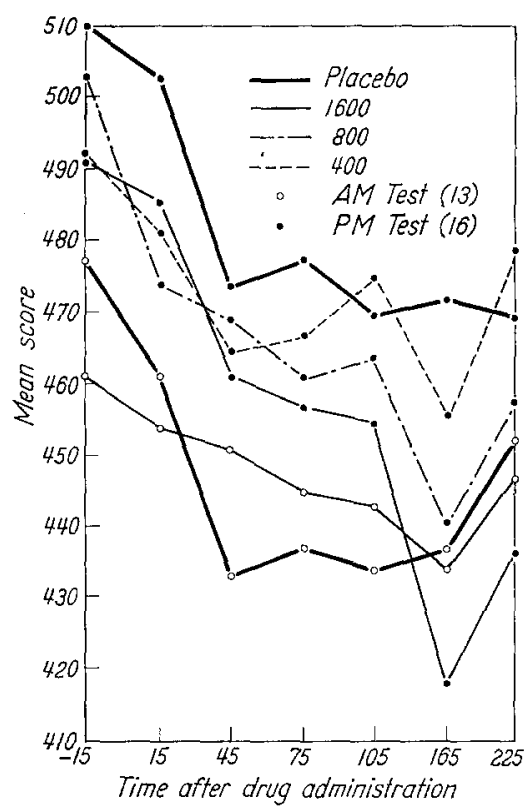

Fig. 1. Visual detection curves under meprobamate and placebo for the morning tests; and (3) a separate test of interaction between drug effects and time of day during which subjects were tested. The group performance curves showing the time and dosage effects of meprobamate on visual detection threshold are shown in Fig. 1. The means and standard deviations under each condition are presented separately in Table 1 . Table 2 presents the analysis of variance related to subject and dosage group for the first eycle before the drug was administered. Before drug ingestion there is no statistically significant difference in threshold between the four dosage groups. The partialling of variance due to drug dosage, time elapsed after drug administration (cycles $3-7$, from $3 / 4$ to $33 / 4$ hours after ingestion), subjects and interactions is presented in Table 3 for the evening tests. Both the drug dosage and time period are significant 
Table 1

Means and standard deviations for visual detection under meprobamate and placebo

\begin{tabular}{|c|c|c|c|c|c|c|c|c|c|c|c|c|c|c|c|c|}
\hline \multirow{3}{*}{$\begin{array}{l}\text { Dosage } \\
\text { mg }\end{array}$} & \multicolumn{14}{|c|}{ Cycle } & \multirow{2}{*}{\multicolumn{2}{|c|}{ Total }} \\
\hline & \multicolumn{2}{|c|}{1} & \multicolumn{2}{|c|}{2} & \multicolumn{2}{|c|}{3} & \multicolumn{2}{|c|}{4} & \multicolumn{2}{|c|}{5} & \multicolumn{2}{|l|}{6} & \multicolumn{2}{|c|}{7} & & \\
\hline & M & SD & M & SD & M & SD & M & SD & M & SD & M & SD & MI & SD & M & SD \\
\hline & 510 & 62 & 502 & 49 & 474 & 55 & 478 & 56 & 470 & 63 & 472 & 67 & 470 & 50 & 482 & 60 \\
\hline 400 & & 62 & 481 & 71 & 464 & 60 & 467 & 54 & 475 & 72 & 456 & 83 & 479 & 57 & 473 & 67 \\
\hline 800 & 503 & 34 & 474 & 58 & 469 & 60 & 461 & 57 & 464 & 59 & 440 & 51 & 458 & 51 & 467 & 56 \\
\hline 1600 & 491 & 49 & 485 & 52 & 461 & 67 & 457 & 84 & 455 & 74 & 418 & 77 & 437 & 80 & 458 & 74 \\
\hline P.M. & 499 & 57 & 486 & 59 & 467 & 61 & 466 & 65 & 466 & 68 & 447 & 73 & 461 & 63 & 470 & 66 \\
\hline & 477 & 67 & 461 & 74 & 433 & $8 \tilde{5}$ & 437 & 68 & 434 & 74 & 437 & 69 & 453 & 72 & 447 & 75 \\
\hline 1600 & 461 & 58 & 454 & 72 & 451 & 68 & 445 & 73 & 443 & 58 & 434 & 78 & 447 & 94 & 448 & 73 \\
\hline A.M. & 469 & 63 & 458 & 73 & 442 & 77 & 441 & 71 & 439 & 67 & 436 & 74 & 450 & 84 & 448 & 73 \\
\hline
\end{tabular}

beyond the .05 level (using the appropriate interactions, since these were significant, as error terms). Inspection of Fig. 1 indicates that the maximum effect for the three drug dosages occurs on the 6th cycle, $2^{3 / 4}$ hours after

Table 2. Evening session, cycle 1: Pre-drug test

\begin{tabular}{r|r|r|r}
\hline Source & df & MS & F \\
\hline Dosage & 3 & 1294.60 & 0.76 \\
Subjects. & 15 & 6830.40 & $4.01 *$ \\
Residual. & 45 & 1701.70 & \\
\hline Total & 63 & &
\end{tabular}

* Significant beyond .01 level drug ingestion, and shortly after the dinner break. The response curves also show that the amount of increase in threshold is related to drug dosage, with subjects showing greatest increase under $1600 \mathrm{mg}$, least under 400 , and none after the first half hour under placebo. On

Table 3. Evening session, trials 3-7: Post-drug tests

\begin{tabular}{|c|c|c|c|}
\hline Source & df & MS & $\mathrm{F}$ \\
\hline Dosage & 3 & 11596.11 & $3.32 *$ \\
\hline Time Period . & 4 & 4600.54 & $2.60^{*}$ \\
\hline Subjects. . . & 15 & 59745.01 & \\
\hline Dosage $\times$ Time . . & 12 & 1307.22 & 1.56 \\
\hline Dosage $\times$ Subjects & 45 & 3493.02 & $4.18 * *$ \\
\hline Time $\times$ Subjects . . . & 60 & 1771.02 & $2.12 * *$ \\
\hline Dosage $\times$ Time $\times$ Subjects & 180 & 835.51 & \\
\hline Total & 319 & & \\
\hline
\end{tabular}

* Significant beyond .05 level ** Significant beyond .01 level

the 7 th cycle, $3 \frac{3 / 4}{4}$ hours after drug administration, the three dosage groups show partial recovery, with the $400 \mathrm{mg}$ group almost back to a pre-drug level. The rate of return to a pre-drug level of performance appears to be related to drug dosage. The significant dosage by 
subject interaction indicates marked individual differences in reactivity to the drug. The dosage by time period interaction is not statistically significant.

Since subjects differ in their response to the drug, one would expect that the variance estimate of subject differences should increase as the drug takes effect, be maximal at the point of greatest drug effect, and be greater under the drug than the no drug condition. Table 1 indicates this to be partially true for the evening tests. The standard deviation for the combined evening tests increases with time and is maximal at cycle 6 , the point at which visual detection was most affected by the drug. Variability was greater under the drug as compared to the no drug condition for the $400 \mathrm{mg}$ and $1600 \mathrm{mg}$ runs, but not for the $800 \mathrm{mg}$ condition. Interestingly, neither of these effects appears to occur in the morning tests where the drug effect was not significant.

A similar analysis was carried out for the morning runs. On the first, or pre-drug cycle, a " $t$ test" to evaluate differences between the means of the drug and placebo groups yielded a critical ratio of 1.01 , which is not statistically significant. The subsequent analysis of variance (Table 4) showed no significant differences attributable to either dosage

Table 4. Morning sessions, trials 3-7: Post-drug tests

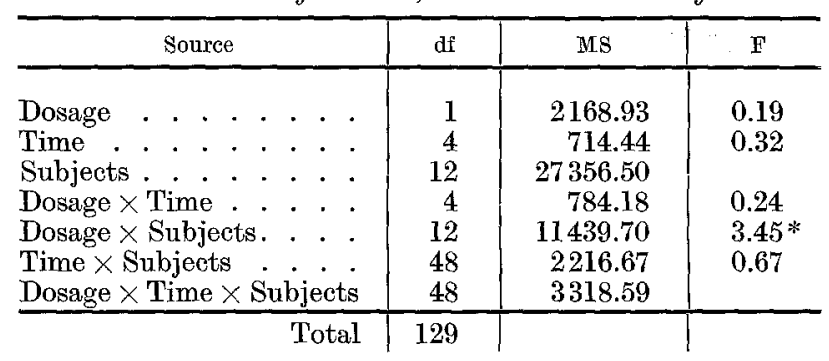

* Significant beyond .05 level.

( $0 \mathrm{vs} 1600 \mathrm{mg}$ ) or to testing cycle. Individual differences in reaction to the drug were significant beyond the .05 level, but none of the interactions approached statistical significance. It should be noted that the drop out of three subjects from the morning tests makes the sample somewhat different from the evening group. However, inspection of the curves for these three subjects under 0 and $1600 \mathrm{mg}$ during the evening tests indicates that they showed essentially the same response effects under drug and placebo as did the other 13 subjects.

In the light of these contradictory findings an analysis of the variance attributable to morning as compared to evening test sessions, and maximum drug dosage vs. placebo, was run. (Table 5. The scores used in the analysis are the sum of the subject's scores from cycles 3 through 7 .) 
Neither time of day, dosage, nor the interactions was statistically significant. However, comparison of the two placebo curves showed subjects significantly poorer during the morning as compared to the evening tests $(t=2.36, p<.05)$. This finding suggests the possibility that diurnal metabolic cycles may affect visual threshold either directly or indirectly, perhaps by altering the motivational state of the subject. If this were the case, a mildly soporific drug such as meprobamate might

Table 5. Morning vs evening (0 vs $1600 \mathrm{mg}$ ) total score cycles 3-7: Post-drug tests

\begin{tabular}{|c|c|c|c|c|}
\hline \multicolumn{2}{|r|}{ Source } & $d f$ & MS & $\mathrm{F}$ \\
\hline Dosage & & 1 & 44958.48 & 2.10 \\
\hline Time &..$\quad$. & 1 & 50034.02 & 0.91 \\
\hline Subjects & . . . & 12 & 270246.44 & \\
\hline Dosage $x$ & Time. . & 1 & 129101.56 & 2.43 \\
\hline Dosage $x$ & Subjects. . & $1 \overline{2}$ & 21443.10 & 0.40 \\
\hline Time $\times S$ & abjects . . . & 12 & 55386.31 & 1.04 \\
\hline Dosage $x$ & Time $\times$ Subjects & 12 & 53182.01 & \\
\hline & Total & 51 & & \\
\hline
\end{tabular}

well have different effects depending upon the time of administration. In the present study a significant decrement in performance after drug ingestion was noted for the evening tests when the base line performance under placebo was high, but was not found during the morning tests when placebo performance was poor.

\section{Discussion}

The significant dosage effects for the evening sessions, as well as the significant dosage by subject interaction for both morning and evening sessions point to a real drug effect on visual detection behavior. However, the significant dosage by subject interaction coupled with the lack of significance for the morning session also points to one of the crucial and as yet unsolved problems in the psychological assessment of drug action: the existence of large individual differences in both sensitivity and reactivity to psycho-active drugs (KonNETsky and HuMPHRIEs, 1957; Kelly, Miller, Marquis, Gerard, and Uhr, 1958). As yet little work has been done on the selection of populations of subjects who will be drug sensitive or drug insensitive, or on the related problem of collecting normative data on different kinds of reactivity to the same drug.

A related problem which has not yet been solved concerns the causes of variability within the same individual over time. This effect was noted in the discrepancy between the data for the morning and evening tests and suggests that the drug effect is partially dependent upon the momentary physiological or psychological state of the subject. 
In this case, the results may be related to changes in the diurnal metabolic rhythm from morning to evening. In any case one might expect both threshold and the ability to compensate for the effects produced by a mildly soporific drug to vary depending upon where in the individual's sleep-wake cycle he was tested.

\section{Summary}

Sixteen male subjects, 21 years and older, were run in a doubleblind own-control design under three dosages of meprobamate $(400$, 800 and $1600 \mathrm{mg}$ ) and matching placebo, to determine response curves on a visual detection task over a four and one-half hour period, from 5:00 to 9:30 p.m. To control for possible daily cycle effects two additional runs under placebo and $1600 \mathrm{mg}$ meprobamate were conducted from 8:00 a.m. to 12:30 p.m.

The evening tests showed statistically significant dosage effects, time effects, and a significant drug by subject interaction. The morning tests showed no difference between performance under placebo as compared to $1600 \mathrm{mg}$ of meprobamate, although there was a significant drug by subject interaction. This differential drug effect was discussed in terms of its possible dependency on the momentary physiological and psychological state of the individual and his diurnal metabolic rhythm.

\section{References}

Blackwell, H. R.: Psychophysical thresholds. Ann Arbor: Engineering Research Institute 1953.

Dickes, R., G. H. Flamm, J. Coltrera, and M. Tobtn: The effect of mephenesin on muscle tension. An experimental study. Arch. Neurol. Psychiat. (Chic.) 74, $590-597(1955)$.

Eysmek, H. J.: Experiments in personality. London: Routledge and Kegan Paul 1959.

-, and S. AIBA: Drugs and personality, V. The effects of stimulant and depressant drugs on the suppression of the primary visual stimulus. J. ment. Sci. 103, $661-665$ (1957).

Kelty, E. L., J. G. Mirler, D. G. Marquis, R. W. Gerard, and L. Uhr: Personality differences and continued meprobamate and prochlorperazine administration. Arch. Neurol. Psychiat. (Chic.) 80, 241-246 (1958).

KORNETSKY, C., and O. HUMrHRIES: Relationship between effects of a number of centrally acting drugs and personality. Arch. Neurol. Psychiat. (Chic.) 77, 235-237 (1947).

UHR, L.: Objectively measured behavioral effects of psycho-active drugs. In: L. UHR and J. G. Mrluter (Eds.), Drugs and Behavior. New York: John Wiley \& Sons 1961.

- A. Platz, and J. G. Miller: Time and dosage effects of meprobamate on simple behavioral tasks. J. gen. Psychol. 68, 317-323 (1963).

Arthur Plate, Ph.D.,

Central NP Research Laboratory Veterans Administration Hospital

Perry Point, Maryland (U.S.A.) 